\title{
Infographics and Their Application in the Educational Process
}

\author{
https://doi.org/10.3991/.vi.14647 \\ Lyaylya Tarkhova $(\bowtie)$ \\ Bashkir State Agrarian University, Ufa, Russian Federation \\ tarkhova@inbox.ru \\ Sergey Tarkhov \\ Ufa State Aviation Technical University, Ufa, Russian Federation \\ Marat Nafikov, Ilshat Akhmetyanov, Dmitry Gusev, Ramzid Akhmarov \\ Bashkir State Agrarian University, Ufa, Russian Federation

\begin{abstract}
The purpose of this study is to improve the effectiveness of the educational process by using infographic content that allows to create interactive infographics with the application of the original markup method. The importance of complex graphic information in the information processes of modern society, the need to know the tools for its creation, rules and techniques of development, as well as the skills of posting infographic information as an integral part of specialists' competence were shown. The paper describes in detail the features of using infographics when creating presentations, mnemonic diagrams, instructions, as well as in the process of searching for information on the Internet. The use of infographics in educational process will reduce language barriers when teaching in an educational institution for both Russian-speaking and foreign students, since infographics improve the perception of educational content regardless of the language environment of students.
\end{abstract}

Keywords - Visual content, infographics, markup maps, educational process, tuition, education.

\section{Introduction}

Wide access to information resources of the Internet global computer network provides users with unique opportunities to quickly obtain the information they need in various fields [1], [2]. Due to objective restrictions imposed by software and hardware environment, information resources were presented mainly in the form of texts in the early stages of Internet development. But at present, modern information and communication technologies and computer equipment allow to widely use graphic and multimedia content [3]. A human being is oriented by nature to the visual perception of the environment. Having high clarity, multimedia content significantly improves the perception of information, its memorization, which is particularly important for edu- 
cational systems [4]. Modern level of development of educational technologies involves a wide use of interactive digital education systems [5], [6], the management of which is based on multiple scenarios, providing students with a high degree of independent decision making when choosing the sequence of learning material [7], [8]. Currently, much attention is paid to developments in the field of adaptive management technologies of digital education [9]-[11]. They allow to make the education process highly effective [12] when using an individualized education style [13], [14]. Much attention is also paid to the analysis of educational outcomes [15]. At the same time, technologies for automated generation of educational content [16], [17] are used. Educational content includes illustrative static and animated infographic materials that are indivisible in terms of their structure and properties.

Complex graphic and multimedia information inevitably leads to the need to change the paradigm of the educational process organization [18], [19]. It can be argued, that the era of multimedia content dominance has inevitably come, and this trend will only increase in the near future [20]. Infographic is one of the components of complex graphical information. Today, infographics and images which they form in the human mind are the basis of the eye-mindedness of most professionals in various subject areas.

Modern knowledge-intensive production of complex industrial products, as well as the development of software products and new technologies are impossible without the use of graphic models such as drawings of parts and components, sketches, schemes and structure diagrams of algorithms, drawings of technical objects. Knowledge of the tools for their creation, rules and techniques for their development, as well as skills for placing infographic information on the Internet is an integral part of the basic competence of specialists. Proper understanding of any profile of infographics importance for the modern educational process, the ability to correctly and rationally involve infographic resources placed on the Internet global computer network in the educational process, and integrate them with modern digital education technologies will make it possible for teachers to realize the training of competent and competitive specialists for the national economy of Russia. At the same time, it should be noted that when working on the Internet with modern media technology and software designed to create and process infographic content (to search, to edit and to convert it) students will indirectly form individual media competence that is so necessary in modern information society [21]. Today graphic information is widely used in various areas of visual communication: in art, which elicit human emotions, evoking a sense of admiration for the beautiful; in social sphere, enabling people to exchange various information; in the educational systems to study various objects and phenomena; in scientific and technological field to implement researches, design and production processes [22]. Obviously, this list can be continued.

Infographic (information graphics) is a graphical method of presenting information and knowledge in the form of a systemically organized set of graphic (image) and text data, the purpose of which is to present sophisticated systematized and structured information in a qualitative an effective way [23]. In other words, infographic is an image, which shows certain information using text and graphics. It is not intended to replace the text of an informational message, but only to help communicate complex 
information to the consumer in a clear and accessible form. "The main difference between infographic and other types of information visualization is its metaphoricity. It is not just a graph, a chart built on the basis of a large amount of data. It is a graph in which visual information analogies from life and subjects of discussion are inserted" [24].

Purpose of the research: Improving the effectiveness of the educational process by using the original method of marking different types of infographic content used in engineering, research and educational activities and allowing to create a complex interactive infographic.

\section{$2 \quad$ Method}

\subsection{Participants of the experiment}

The research was conducted on the basis of:

- The Department of Informatics of the Federal State Educational Institution of Higher Education Ufa State Aviation Technical University (USATU);

- The Department of Mechanics and Engineering Graphics of the Federal State Educational Institution of Higher Education Bashkir State Agrarian University (BSAU).

The experimental study is devoted to the analysis of the results of the educational process based on the paradigm of the wide use of infographic content. Full and parttime students of all five years of studies of USATU and BSAU took part in the research. The total number of students participating in the study was 578 people, including: 156 (USATU) and 121 (BSAU) first-year students; 57 (USATU) and 152 (BSAU) second-year students; 54 (USATU) third-year students; 38 (USATU) fifthyear students.

The study was conducted during 2017-2018 and 2018-2019 academic years when students studied general educational subjects ("Descriptive geometry and engineering graphics", "CAD Basics", "Computer science", "Computer science and information technology"), special disciplines ("Legal and information support of organizational and technical systems" and "Modeling of production and transport-technological processes in organizational and technical systems"), and during their graduate qualification works. During the experiment Gefest e-learning adaptive system was used [8], [25], which is based on the object technology for storing and processing of a text, graphic, and multimedia educational content [26].

\subsection{Research tools}

To assess the quality of academic works containing infographics, the degree of educational content uptake and the level of forced competence when studying academic disciplines, the following quality management system tools were used: Pareto diagrams that allow to identify the most significant and important factors, to define the 
priority of actions necessary to solve the identified problem; checklists used to record the results of observations and measurements of controlled indicators [27]. The information obtained with the use of a checklist is more systematic compared to standard data collection.

\subsection{Experiment and data analysis}

The method of collecting information using checklists was used to study the quality of infographic materials, which are part of the students ' academic papers (reports on laboratory work, explanatory notes to computational and graphic works and presentations for reports on students individual work). Information was collected by teachers who were conducting laboratory and practical classes in training groups. Filling in a checklist is not formalized and doesn't require much time. Thus, checklist filling was conducted both during laboratory work defence and during grading students' materials which were presented either in the form of hard copies, or in electronic form (documents created by word processors). Qualitative evaluation of infographic materials was performed according to six most significant indicators for both presentation and informational infographics.

The effectiveness of the educational content was assessed when using interactive infographics containing markup maps. The assessment was performed based on the results of a diagnostic test and solution of problems extracted from the e-learning system database that students worked with.

Classification, structuring, and statistical processing of experimental data collected using checklists and e-learning systems, as well as construction of diagrams were performed in the Microsoft Excel spreadsheet processor.

\section{Results}

Infographic is a highly effective visualization tool, which allows to present organized and structured information about any event, fact, object or phenomenon in a graphical form. Today infographics are increasingly used not only in the media, social and economic spheres, but also in science, engineering and education.

After analyzing the use of infographics in scientific, technical and educational fields, we classify them into the following types:

- Presentation infographic, i.e. non-formalized infographics containing information for presenting data about something (results of scientific and technical research, development of technical projects, educational information, etc.);

- Mnemonic infographics, i.e. an unformalized infographic that allows to visualize a device, composition and structure of something, to give specific features and characteristics, as well as to show the sequence of operations when solving professional tasks in a particular subject area;

- Specialized infographics, i.e. formalized and standardized infographics that allow to create different types of object and process models: functional system models; 
diagrams of business processes; infological database models; mind maps or mental maps (relationship diagrams); cause consequence diagrams; organizational charts; scheduled plans; block diagrams, schemes of algorithms and programs; flow graphs, technical drawings, sketches, drafts, etc.;

- Directive infographics, i.e. unformalized or formalized infographics that contain a sequential set of instructions that establish the order of actions (algorithm) when working with an object or the sequence of implementation of a process: orders, rules, instructions, technological maps, educational and technical posters, etc.

- Cartographic infographics - formalized and non-formalized (combined), usually interactive infographics, combining maps or satellite images in geographic information systems (programs) with textual information and photo images retrieved of the database by a user when required (for example, Yandex Maps, Google Maps, navigation software, etc.).

Infographics can be made in a single informational style with the use of a defined set of typical or standardized graphic objects (formalized infographics) or presented as a set of objects (photos, maps, charts, diagrams, icons, and pointers) that are heterogeneous in structure, design, and presentation method (data type) and united by a common information content. This type of infographicsis called collage-infografics.

From the point of view of presenting graphic information in a digital form, infographics can be made in a vector or bit map format. Infographics made in a vector format make it easy to scale images without losing quality. At the same time, photo images that are saved in a bit map format cannot be presented in a vector format. The disadvantage of bit map formats is the loss of quality when scaling. It is advisable to develop and save a complex infographic content in computer graphics formats that allow combining and storing graphic objects as a set of vector and bitmap fragments.

Infographics are widely used by specialists of various branches of knowledge in in their professional activities. Among these specialists are analysts, designers, journalists, political strategists, scientific workers, engineers, technicians, teachers, etc. Inforgraphics change the way of thinking, allowing to quickly and effectively acquire information through capacious and short visual images.

Computer skills and knowledge of technologies when visualizing ideas with the use of infographics are undoubtedly necessary for specialists in any subject area. This requires solid background in the field of modern computer technologies, as well as understanding of features of graphic information in terms of translating it into a computer format. A professional infographic developer must also know the basics of design, have good aesthetic taste and be able to think fairly broadly.

One of the key competencies of a modern specialist in any subject area is knowledge of the principles and basic rules of making presentations, the ability to create and correctly design digital presentation slides containing presentation infographics, and, if necessary, to post presentations on the Internet. The results of the analysis of students ' presentation activity show that up to $80 \%$ of presentations prepared by first, second- and third-year students do not meet the generally accepted requirements for their design and material representation. At the same time, it should be noted that there is no rational correlation between the amount of texts on presenta- 
tion slides and graphic objects. Information content of slides is usually a solid text or large tables typed using small print that does not contrast well with dark or bright slide background. The other extreme is that presentation slides consist only of photos and drawings without any legend, and the title of the slide is often missing. Mistakes that students usually make creating presentations are shown in figure 1 .

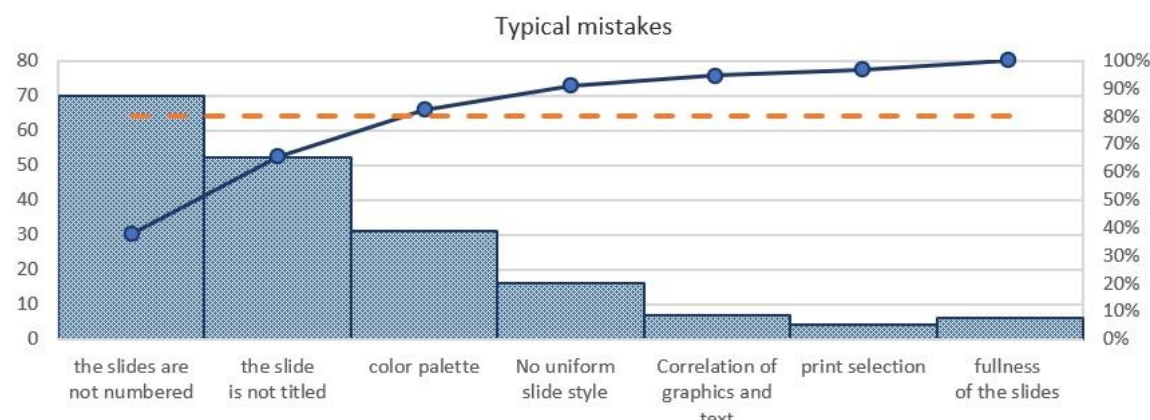

Fig. 1. Results of the analysis of typical mistakes made during presentation designing

Any presentation developer should understand that the most effective way to put information on slides is to use infographics. If infographics are used during the report accompanied by a presentation, they allow to present information clearly and efficiently as well as to implement effective team work [28]. The rules for developing and creating computer presentations are not considered in the paper, since this material is well represented in Internet resources.

Another important competence of a modern specialist are skills in developing infographics of mnemonic diagrams, which are widely used:

- By students (preparation of abstracts, presentations, reports, explanatory notes for course papers and projects, final qualifying works) and by teachers (preparation of educational materials, presentations) during the educational process;

- In scientific research (preparation of articles, lectures, reports, projects, dissertations, etc.);

- In engineering (presentation of the design work results; diagrams describing design and operation of assemblies and mechanisms; instructions; educational and technical posters; algorithms, etc.).

Mnemonic diagrams are usually created using special, thematically defined sets of graphic symbols typical for a particular scientific, technical or educational field. In most cases these symbols are included in dedicated software (highly specialized or universal for a particular subject area). Examples include software products such as MS Visio, which allows to create diagrams, graphs, charts, schedules, plans, maps, etc. using various pattern categories, or XMind, which helps to create mind maps, Ishikawa diagrams (also known as fishbone or cause consequence diagrams), tree diagrams, and logical diagrams. 
A technician must have competence in the development of documentation accompanying the design process and describing a device, the function principle and rules for working with various devices, mechanisms, software, etc. Acquisition of knowledge and skills for creating specialized and directive infographics plays an important role in formation of this competence. First of all, a specialist should possess knowledge of the methodology of functional and infological modeling. He must be able to design mind maps, cause consequence and organizational diagrams, schedule charts, block diagrams, schemes for algorithms and programs, flow graph, instructions, technological cards etc. with the use of special software tools, and standards and techniques accepted in a particular scientific and technical area. For example, the infographic detailed model of the quality management system (so-called quality loop), based on the process approach and used by enterprises and organizations of the Russian Federation, is stipulated by the state standard. At the same time, all the basic concepts in the field of quality and their relationships are given in the form of infographic schemes.

Having analyzed students' papers, containing infographic objects presented in the form of mnemonic, specialized and directive infographics, the following categories of typical mistakes were revealed in order of their importance (figure 2):

- The key idea of an infographic object (a model of a system, object, or process) has not been worked out, and it does not contain any meaningful information about the simulated object or process

- An attempt was made to focus attention in an infographic object on insignificant information that does not reflect the main essence of the simulated object or process

- Graphic symbols used on an infographic object do not correspond to the object or process being modeled, which in general makes it difficult to acquire information

- An infographic object does not have a necessary text, containing key information about the simulated object or process, which generally makes it difficult to acquire information

- The infographic object transmits necessary information, but is designed in breach of the requirements imposed for pictures (illustrations) in technical documents and presentations

- Too small, unreadable print used for text legends; small or (less often) too large icons (graphic symbols)

- Other mistakes (bad linking of individual image elements; blurred communication lines and contours of individual areas of the infographic object) 


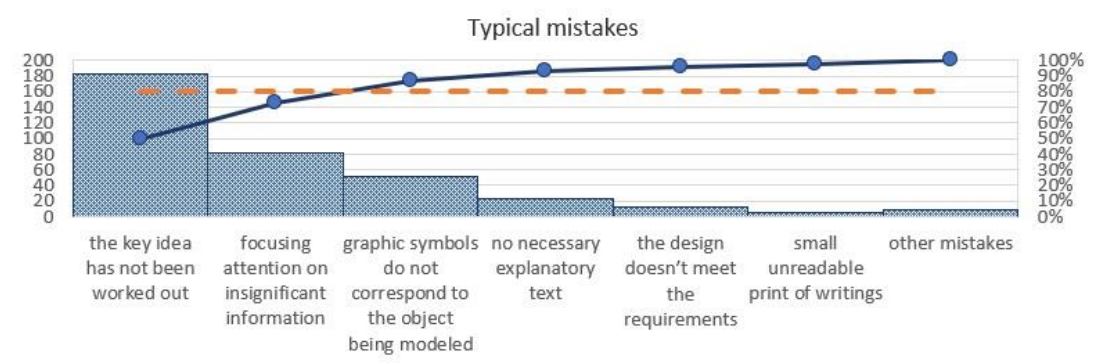

Fig. 2. Results of the typical mistakes analysis

The above mentioned requires the teacher to focus on the formation of students ' competence in the field of creating high-quality infographics, starting with junior courses and taking into account typical mistakes made when developing them.

Various types of infographics allow not only to present completed information to the user, but also to implement searching for information in Internet search systems. Modern Internet search systems are based on the use of highly effective semantic search algorithms in large databulks. They are designed for widely used, prestored queries, which leads to displaying of both relevant and pertinent data, when searching for highly specialized skill information. Sometimes it's difficult to find the necessary information among the data presented by the search system. One of the possible ways for users to solve the problem of finding information they are interested in is the search of images (Yandex Images, Google Images, Nigma Pictures), among which infographics are readily available. For example, for the user query "how does the engine work" there will be many mnemonic infographic diagrams in Yandex-Pictures search system. Users can select by eye the desired engine type and, if necessary, go to the appropriate Internet resources with a detailed description. During selection of a Yandex-video, users will find a lot of educational and informational videos. A similar query in Google-Pictures search system using the advanced search technology will also allow to find animated diagrams of the engine construction. At the same time, it is important to organize the search properly, using advanced capabilities of the search systems (size and type of images, novelty, rights to use, etc.).

The effectiveness of infographic content can be significantly increased by making it interactive, using the method to structure images of graphical models of objects and processes and managing educational content transitions [29] (figure 3). 


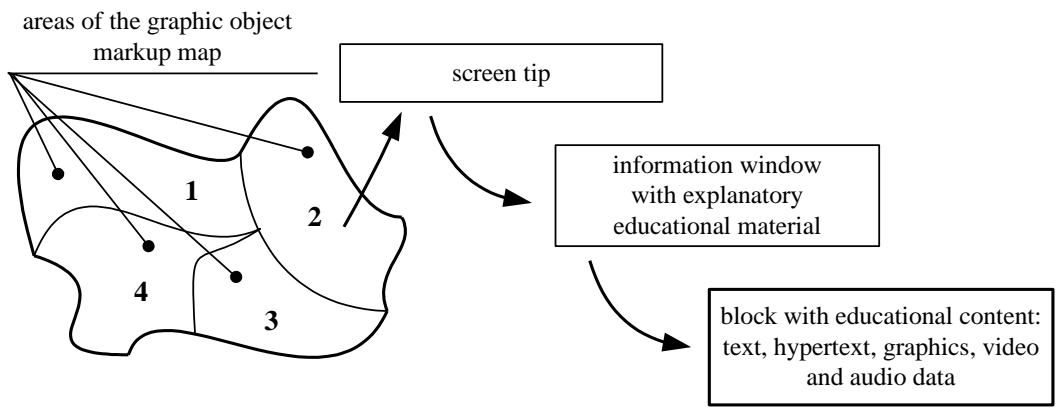

Fig. 3. Educational content transitions based on markup maps of the graphical object

This method is used to study engineering disciplines ("descriptive geometry and engineering graphics", "CAD Basics", "Computer Science", "Computer science and Information Technology", etc.). Learning material used to study these disciplines is characterized by a significant number of graphic models of objects and processes (sketches, drafts, diagrams, technical drawings, three-dimensional models), which must be considered as a complex structured graphic content.

Infographic content markup maps allow to implement interactivity using hypertext technologies:

1. Following hyperlinks to hypertext documents associated with the infographic object markup map that replace the current infographic object in the browser's window.

2. Following hyperlinks to hypertext documents associated with the infographic object markup map that are opened in the browser's window.

3. Following hyperlinks to a new infographic object (or graphic object) that replaces the current infographic object in the browser's window.

4. Following hyperlinks to a new infographic object (or graphic object) that is opened in the browser's window.

5. Screentips in various areas of the infographic object without performing any other actions.

6. Following hyperlinks to infographic objects (or graphic objects) that replace the current infographic object when an event occurs, such as a single or double mouse click on the selected area of the infographic object's markup map, etc.

From the first to the fourth inclusive implementation variations for hyperlinks are traditionally used in hypertext materials and are not specific to markup maps.

The fifth and sixth variations for implementing hyperlinks associated with graphic image markup maps are rarely used in hypertext documents and are of particular interest from the point of view of implementing new methodology for managing educational content and reference materials. At the same time, it should be noted that the fifth and sixth variants of hyperlinks implementation can be used together, i.e. when selecting a certain area of the graphic image markup map, a screentip will be displayed before the event specified in the markup map [29]. An example of implement- 
ing graphic object markup maps in the educational content of the Gefest e-learning system is shown in figure 4 .

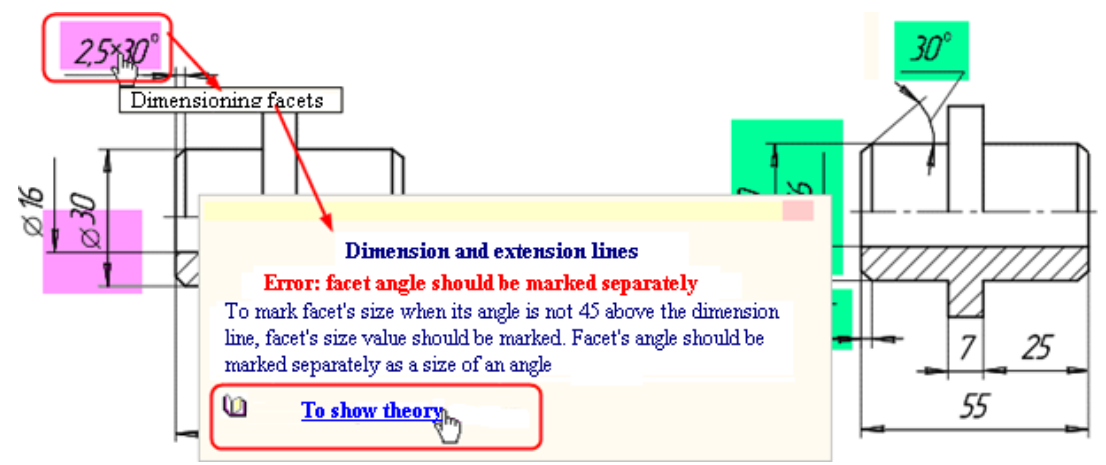

Fig. 4. Use of graphic images markup maps in the analysis of typical mistakes when studying drafts dimensioning

The use of infographic objects markup maps makes a natural need to modify methodology and training management process (procedure), during which graphic images structuring should be taken into account. When introducing a new infographic content prepared using graphic image markup maps [30], students were given the opportunity to independently decide how to work with educational material-and choose between marked interactive infographic content or unmarked infographic content. During the work, $86 \%$ of students chose the technology of working with interactive infographic content in the course of training.

Practical application of infographic content with markup maps when studying graphic engineering disciplines has shown its high efficiency as the level of coping with the course content during individual work of students has increased by an average of $20-25 \%$ (figure 5).

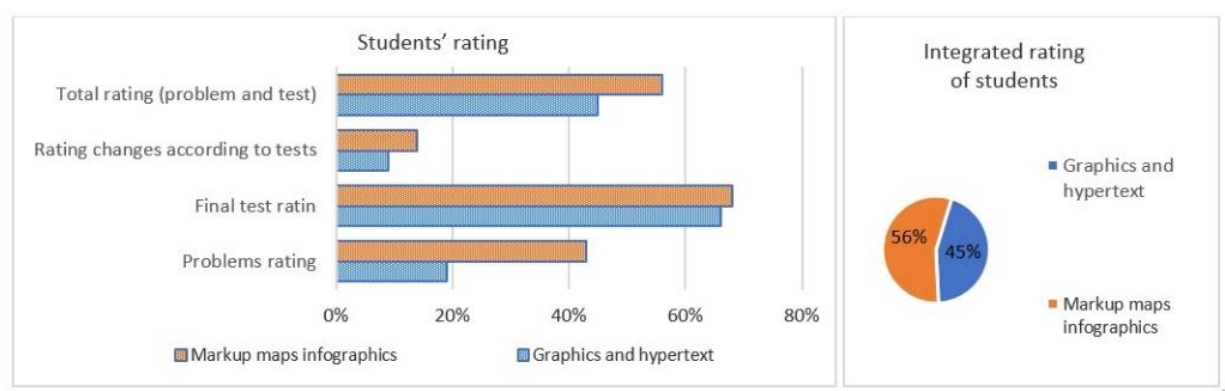

Fig. 5. Assessment of the quality of students ' learning of educational material

Switching to new educational standards, a competency-based approach, and widespread introduction of e-learning content in the educational process requires to revise 
the ways in which educational information is developed and presented to students. Infographic content plays an important role in this area.

The study results show, that junior students have relatively low competence in the field of infographic preparation. When designing presentations, mnemonic diagrams and infographic content of specialized and declarative infographics, students make a number of typical mistakes that should be paid attention to during the learning process: poor elaboration of the key idea of an infographic object; emphasis on insignificant information in an infographic object; use of graphic symbols on an infographic object that do not correspond to the simulated object or process; absence of the necessary text on an infographic object that contain key information about the simulated object or process; design of an infographic object in violation of the established requirements.

Systematic training of students to work with infographics and to search for information using infographics on the Internet, contributes to the formation of media competence of the individual, which allows a specialist from any area of expertise to effectively solve the tasks facing him: to effectively search search for information on the Internet; to properly present the results of the work, including infographic content in their structure; to present the results of the work using presentations. The use of complex structured infographics with graphic image markup maps helps to improve understanding and learning of complex educational material (on average by $20-25 \%$ ). It is one of the effective means of improving the quality of education in the training of specialists.

\section{Discussion}

The key focus of this paper is the interactive infographic content as one of the important components of training and technical information presentation, its classification, methods of creation, submission, processing, and usage in the educational process of the University and its impact on students learning.

Information can be presented in the form of signals (light and sound signals) or symbols (numeric, text), as well as in graphical form [31]. The graphical representation of information is based on the use of data presented in the form of graphical images formed from graphical primitives to form an image: point, line, circle, etc. Graphic form includes drawings, pictograms, schemes, drafts, diagrams, graphs, photos, and so on. This is the most ancient way of presenting information, which appeared long before the written language [32]. Graphic information can be defined as a complete and well-ordered set of data (graphic primitives) deposited on a physical storage medium that can store data for a long time in its structure [33]. Carriers of such information can be stone, wood, paper, glass, metal, plastics, silicon (other types of semiconductors), tape with a magnetized layer (in bobbins and reels), photographic material, plastic with special properties (for example, in optical disks), and other materials [34].

Den Roem, a founder of Digital Roam Inc consulting company says, that business problems (whatever they are) can be solved by creating simple images. Any problems 
that we can define are much more clearly expressed with the use of images. Images can be even the simplest: a rectangle, a circle, a contour object and arrows connecting them. We are all born visual thinkers (even if we don't think so, it's still a fact). Images we need are extremely simple, and anyone able to see can solve problems using them [35].

Speaking about the information capacity (information entropy) of an image, it should be noted that it fully depends on the rules of interpretation of graphic information that establish the correspondence between the graphic image and the information in it. For example, road signs defined by traffic rules can only be correctly understood by people who know these rules. At the same time, the same sign carries different information for different road users: the pedestrian crossing sign defines different actions for two groups of road users-drivers and pedestrians. This sign does not carry significant information for a person who does not know the traffic rules, for example, for a small child. He only sees an image of a walking man on it. Only a specialist can read a technical drawing, as he has knowledge of engineering documentation compiling. A computer science expert can only understand an algorithm diagram. At the same time, we can often understand the meaning of graphic images using associative thinking and our life experience. Thus, it can be argued that visual content transmits information to the consumer if the rules for processing it is known, or if it is associated with a known object or process. High information capacity (information entropy) of multimedia content and infographics is explained by the fact that the entropy of the entire image is equal to the limit value of the conditional entropy of one image element multiplied by the total number of elements [36].

In contrast to text and audio information, graphic information cannot be subjected to strict systematization, as is done, for example, for text information brought to a certain system using the alphabet. It is impossible to create a universal graphic alphabet that formalizes the structure of any images. It is the difference that separates standard writing and modern figurative activity. This does not mean that it is not possible to create special character sets and establish rules for generating and processing graphic images in certain subject areas. Special sign systems that allow to create diagrams, drawings, technical drawings and other special graphic objects are widely used in science and technology, as well as in everyday life. An example is iconic (figurative) signs. They differ in the fact that their images are recognizable and similar to real objects. In iconic signs (icons (eikon (ancient Greek), icon (English.)- image, similarity)) the form duplicates the content. It is possible to determine the value of the sign by its shape, i.e. the shape of the sign takes on a role of the value. Such a sign does not need to be translated, because it is similar to the object it is associated with. Today, such signs are everywhere: at railway stations, airports, shops, catering establishments and other public places where special signs are required, the values of which are independent of the language environment [37]. Iconic signs are widely used in modern software and in the Internet global computer network. Examples of using special sets of graphic symbols are standards used in scientific and technical area.

Why is graphic information so popular in the modern Internet space? The matter is that graphical way of presenting data allows to effectively store information, as well as share it, and it is the most capacious form of information representation and pro- 
cessing. The use of infographics in the educational process helps to interest the audience, draw attention to the subject material, inform and subsequently apply received information [38].

The classification of infographics is widely represented on the Internet. Head of the infographic Department of the Russian state news agency RIA-Novosti A. Novichkov identifies three types of infographic sources [39]: "Analytical infographics" - contains statistical digital indicators derived from analytical research; "News infographics" includes news material (comparison of new and old, chronology, analytics, and consequences) that provides a visual explanation of the event; "Reconstruction Infographics" - includes data about an event or process that recreates the dynamics in chronological order. Novichkov A. also notes the directions of using infographics in the economic and social spheres: business infographics for presentation of projects, infographics as advertising for promotion of goods and services. This classification does not cover scientific and technical area of infographics application. In the Internet, infographics can reflect specific information material, presenting it as a single graphical object or a set of such objects collected in one block and interconnected with each other. It also can be separate, presented as separate blocks that are not related to each other.

The main forms of infographic communication can be static images, dynamic (moving) images, and interactive interfaces [40]. Static infographics are graphic images (drawing) created by their author and remaining unchanged during their study and analysis. Dynamic infographics are represented as graphical images containing time-variable data (animation). At the same time, both the whole image and its individual parts can be animated. Computer presentations are an example of dynamic infographics that have animation effects configured and activated. Interactive infographics are a combination of regular infographics and image content management software, the data for which can change depending on the parameters selected or set by the user. This type of infographics can be used, for example, in various calculation services. Interactive graphics can also display data in real time without user's participation [41].

Infographics are widely available on the Internet. A good example of them is the website of the Ministry of Education of the Russian Federation, which contains a special section "Infographics" (http://минобрнауки.рф/инфографика), presenting information grouped into sections: "Universities", "State Final Examination", "For foreign citizens", "Pre-school education", "Inclusive education", "Science", "Labor and health Protection", "Federal State Education Standards", "Project 5-100", "Statistical information", "Schools". The infographic content on this website allows to get information on the topic of interest in a convenient visual form. For example, in the section "Statistical information", among other information materials, there is a "Plan of activities of the Ministry of Education and Science of the Russian Federation for 2013-2018", showing the targets of the Ministry of Education and Science of Russia for 2018 using text, images and numbers.

Other studies [31] show that $90 \%$ of the information processed by the brain is visual information. The following features of human perception and subsequent processing of information are noted: 
- People are born with the ability to quickly recognize images

- A text which contains graphic images is understood and remembered better than a text without images

- All images attract our attention in one way or another

- The brain processes images 60,000 times faster than text

- Internal sensations occur in less than 3 seconds during the process of perception of the analyzed information

- Emotions arise 5 times faster than a conscious reaction

- The area of the brain that processes images is located right next to the area that processes emotions

- Emotions leave a longer impression than a conscious thought

The high speed of image perception and processing by the human brain is confirmed by research performed by neuroscientists from the Massachusetts Institute of technology [42]. During the study, a minimum time required for a human brain to process a displayed image was determined. This indicator is equal to 13 milliseconds. This is significantly less than expected. Previously, scientists estimated the processing time of information to be about 100 milliseconds. At the same time, it should be noted that test persons were shown a series of 6 or 12 images with an interval of 13-80 milliseconds. They should not have actually recognized and analyzed the images presented to them, but they should have signaled that they saw a certain type of image, such as "picnic" or "smiling couple". The indicator of 13 milliseconds was the minimum possible time for updating the image on a computer monitor. So, as researchers not, it was impossible to further reduce the time limit in the experiment. The speed of the brain is likely to be even higher than it was found during this study. At the same time, scientists assume that image processing in the human brain continues after "background" viewing, that is, longer than 13 milliseconds. The image itself is not "erased" from memory after 13 milliseconds and remains there for further processing.

All of the above confirms the need for extensive use of visual content to present information. It is obvious that rational combination of graphics and explanatory text (infographics) will lead to a better understanding of the information presented in this form.

\section{Conclusion}

The results of our research show that the following types of infographics are used in the modern educational process: presentation infographics containing background information; infographics of mnemonic diagrams, allowing to visualize the device, the composition and structure of something, showing specific features and characteristics; specialized infographics that allow to create different types of models of objects and processes; directive infographics containing a consistent set of rules establishing the order of steps (algorithm) when working with any object; a cartographic infographic that combines geographic and information systems (programs), maps or satellite images with textual information and images. An experimental study conducted over the 
past three years with students of Ufa State Aviation Technical University and Bashkir State Agrarian University has revealed problems associated with the use of infographics in the study of general and special disciplines. The key mistakes made by students when using infographics in their works were identified, among which the most significant are: poor elaboration of the key idea of the infographic object; attempt to focus attention in an infographic object on insignificant information that does not reflect the main essence of the simulated object or process; violation of the established requirements for the design of an infographic object. Systematic training of students to work with infographics and to search for information using infographics on the Internet, contributes to the formation of media competence of the individual, which allows a specialist from any subject area to effectively solve the tasks facing him: to effectively search search for information on the Internet; to properly present the results of the work including infographic content in their structure; to present the results of the work using presentations. The effectiveness of infographic content used in e-learning systems can be significantly increased by making it interactive, using the method to structure images of graphical models of objects and processes and managing educational content transitions. The high attractiveness of interactive infographic content was shown: $86 \%$ of students chose the technology of working with interactive infographic content in the course of their studies. The use of complex structured infographics with graphic image markup maps helps to improve understanding and learning of complex educational material (on average by 20-25\%). It is one of the effective means of improving the quality of education in the training of specialists.

\section{$6 \quad$ References}

[1] Terzi, H. (2016). A taxonomy for evaluating information credibility on the internet. Department of information systems. Rhodes university, pp. 48.

[2] Testov, V.A. (2019). Beauty in mathematical education: synergetic worldview. The Education and science journal, 21(2), 9-26. (In Russian) https://doi.org/10.17853/1994-56392019-2-9-26

[3] Kasture, R., \& Dixit, A. (2014). Internet Image Search Based On User Intention. International Journal, 2(6), 164-169.

[4] Osin, A. (2005). Multimedia in education: context of Information technology. Moscow: "Publishing service" agency, pp. 320.

[5] Elena Gallagher, S., O’Dulain, M., O’Mahony, N., Kehoe, C., McCarthy, F., \& Morgan, G. (2017). Instructor-provided summary infographics to support online learning. Educational Media International, 54(2), 129-147. https://doi.org/10.1080/09523987.2017.136279

[6] García-Peñalvo, F., \& Pardo, A. (2015). Una revisión actualizada del concepto de eLearning. Décimo Aniversario. Education in the Knowledge Society, 16(1), 119-144. http://doi.org/10.14201/eks2015161119144

[7] Lau, A., \& Tsui, E. (2009). Knowledge management perspective on e-learning effectiveness. Knowledge-based systems, 22(4), 324-325. https://doi.org/10.1016/j.knosys.2009.02. $\underline{014}$

[8] Cherkasov, A., Bratanovskii, S. N., Koroleva, L. A., Zimovets, L. G. (2019). The Development of the School Education System in Vologda Governorate (1725-1917). Part 2. European Journal of Contemporary Education, 8(2), 418-424. 
[9] Al-Omari, M., Carter, J., \& Chiclana, F. (2016). A hybrid approach for supporting adaptivity in e-learning environments. The International Journal of Information and Learning Technology, 33(56), 333-348. https://doi.org/10.1108/IJILT-04-2016-0014

[10] Bognar, B. (2016). Theoretical backgrounds of e-learning. Croatian Journal of Education: Hrvatski časopis za odgoj i obrazovanje, 18(1), 225-256. https://doi.org/10.15516/cje.v18 $\underline{\mathrm{i} 1.1475}$

[11] Sanchez-Santillan, M., Paule-Ruiz, M., Cerezo, R., \& Alvarez-Garcia, V. (2016). MeL: a dynamic adaptive model of the learning process in eLearning. Anales De Psicología/Annals of Psychology, 32(1), 106-114. https://doi.org/10.6018/analesps.32.1.1950 $\underline{71}$

[12] Tergan, S., \& Keller, T. (2005). Digital concept maps for managing knowledge and information. Knowledge and infromation visualization: searching for synergies. Lecture notes in computer science, 3426, 185-204. https://doi.org/10.1007/11510154_10

[13] Özyurt, Ö., \& Özyurt, H. (2015). Learning style based individualized adaptive e-learning environments: Content analysis of the articles published from 2005 to 2014. Computers in Human Behavior, 52, 349-358. https://doi.org/10.1016/j.chb.2015.06.020

[14] Poulová, P., \& Simonova, I. (2012, April). Flexible e-learning: online courses tailored to student's needs. In Proceedings of the 9th International Scientific Conference on Distance Learning in Applied Informatics (DIVAI 2012). UKF Nitra, pp. 251-260.

[15] Gomez-Aguilar, D.., Garcia-Penalvo, F., \& Theron R. (2014). Visual analytics in elearning. Profesional de la informacion, 23(3), 236-245. https://doi.org/10.3145/epi.2014. may.03

[16] Rani, M., Nayak, R., \& Vyas, O. (2015). An ontology-based adaptive personalized elearning system, assisted by software agents on cloud storage. Knowledge-Based Systems, 90, 33-48. https://doi.org/10.1016/j.knosys.2015.10.002

[17] Shehadeh, A., Felfernig, A., Stettinger, M., Jeran, M., \& Reiterer, S. (2017). Automated learning content generation from knowledge bases in the STUDYBATTLES environment. International journal of software engineering and knowledge engineering, 27(9-10), 13871408. https://doi.org/10.1142/S0218194017400022

[18] İslamoğlu, H., Ay, O., İlic, U., Mercimek, B., Dönmez, P., Kuzu, A., \& Odabaş1, F. (2015). Infographics: A New Competency Area for Teacher Candidates. Cypriot Journal of Educational Sciences, 10(1), 32-39.

[19] Alford, K. (2019). The Rise of Infographics: Why Teachers and Teacher Educators Should Take Heed. Teaching/Writing: The Journal of Writing Teacher Education, 7(1), 7.

[20] Martix, S., \& Hodson, J. (2014). Teaching with Infographics: Practising New Digital Competencies and Visual Literacies. Journal of Pedagogic Development, 3(2), 17-27.

[21] Tarkhov, S. (2016). Media competence and e-learning: problems, tasks, solutions. Media education, 4, 66-80.

[22] Kantor, V.Z. \& Proekt, Y.L. (2019). Inclusive higher education: socio-psychological wellbeing of students. The Education and science journal, 21(2), 51-73. (In Russian) https:// doi.org/10.17853/1994-5639-2019-2-51-73

[23] Newsom, D., \& Haynes, J. (2010). Public Relations Writing: Form \& Style. Cengage Learning, pp. 448.

[24] Ermolaeva, J., Gerasimov, I., \& Lopukhova, O. (2014). Infographics as a way to visualize educational information. Scientific and methodological electronic journal "Concept", 11(November), 26-30.

[25] Tarkhov, S., \& Minasov, Sh. (2005). Realization of Adaptive Teaching Technologies in Networking Data-Tutorial System «Gefest». Proceedings of the 7 th International Workshop on Computer Science and Information Technologies. Ufa, Russia, vol. 2, pp. 76-80. 
[26] Tarkhov, S., Minasov, Sh., Minasova, N., \& Tarkhova, L. (2018). Storage and processing technologies of cognitive content for e-learning systems. Proceedings of the 3rd RussianPacific Conference on Computer Technology and Applications. Vladivostok, Russia. https ://doi.org/10.1109/rpc.2018.8482185

[27] Ehling, M., Körner, T., Bergdahl, M., Elvers, E., Földesi, E., Kron, A., Lohauß, P., Mag, K., Morais, V., Nimmergut, A., Viggo Sæbø, H., Szép, K., Timm, U., \& João Zilhão, M. (2007). Handbook on Data Quality Assessment Methods and Tools. Wiesbaden, pp. 411.

[28] Sibbet, D. (2013). Visualize it! How to use graphics, stickers, and intelligence maps for teamwork. Moscow: Alpina Publisher. pp.280.

[29] Minasova, N., Tarkhov, S., \& Tarkhova, L. (2015). Management of educational disciplines content in e-learning systems based on the method of image structuring. Fundamental research, 7, 338-342.

[30] Tarkhov, S., \& Tarkhova, L. (2011). Dimensioning draft parts. Electronic textbook on engineering graphics. Certificate of official registration in the Joint Fund of Electronic Resources "Science and education", No. 17068 of 10.05.2011.

[31] Walter, E. (2014). The power of visual storytelling: how to use visuals, videos, and social media to market your brand. McGraw-Hill, pp. 256.

[32] Von Petzinger, G. (2017). The First Signs: Unlocking the Mysteries of the World's Oldest Symbols. Simon and Schuster, pp. 320.

[33] Nikulin, E. (2018). Computer graphics. Models and algorithms. 2nd ed. Lan pub, pp. 708.

[34] Hilbert, M., \& López, P. (2011). The world's technological capacity to store, communicate, and compute information. science, 332(6025), 60-65. https://doi.org/10.1126/science. 1200970

[35] Roem, D. (2013). Practice of visual thinking. Original method for solving complex problems, pp. 369

[36] Pratt, W. (2007). Digital Image Processing: PIKS Scientific Inside. Wiley, pp. 808.

[37] Pocheptsov, G. (2000). Communication technologies of the twentieth century. Moscow. Refl-book pub. Kiev. Wackler, pp. 352.

[38] Kiikova, E., Sobolevskaia, E., \& Kiikova, D. (2017). Analysis of the effectiveness of infographics in the educational process of a higher educational institution. Modern problems of science and education, 6 .

[39] Novichkov, A. (2014). Types of infographics. Retrieved from http://comagency.ru/vidyinfografiki

[40] Lankow, J., Ritchie, J., \& Crooks, R. (2012). Infographics: The power of visual storytelling. Wiley, pp. 264.

[41] Lankow, J., Ritchie, J., \& Crooks, R. (2012). Infographics: The Power of Visual Storytelling, John Wiley \& Sons, pp. 272.

[42] Potter, M. C., Wyble, B., Hagmann, C. E., \& McCourt, E. S. (2014). Detecting meaning in RSVP at 13 ms per picture. Attention, Perception, \& Psychophysics, 76(2), 270-279. https ://doi.org/10.3758/s13414-013-0605-z

\section{$7 \quad$ Authors}

Lyaylya Tarkhova has PhD degree in Technical Sciences. She has been working at Bashkir State Agrarian University since 1988 in different positions. Now she is working as head of department "Mechanics and engineering graphics". The field of scientific research - information technologies in learning. 
Sergey Tarkhov has MD degree in Technical Sciences. He has been working in teaching positions at the Ufa State Aviation Technical University since 1980. Now he is working as Professor at Department of Computer Science. The field of scientific research - design of information and learning environments for educational systems.

Marat Nafikov - mechanical engineer. Doctor of Technical Sciences, Professor of the Mechanical Department of Bashkir State Agrarian University. The field of scientific interests: soldering, metal welding, restoration of worn-out parts of machines and equipment by cladding. Marat Nafikov has 35 inventions, he is the author of about 170 scientific works. Under his leadership, three candidate dissertations were prepared and defended at the University (I. I. Zagirov and A. A. Zainullin, etc.).

Ilshat Akhmetyanov has $\mathrm{PhD}$ degree in Technical Sciences. He has been working at Bashkir State Agrarian University since 1998 in different positions. Now he is working as assistant professor at department "Mechanics and engineering graphics". Author of several methodological developments. He reads lectures, conducts laboratory and practical classes. An active public figure, curator of the study group. Works on a doctoral dissertation.

Dmitry Gusev has $\mathrm{PhD}$ degree in Technical Sciences. Now he is working as senior lecturer at department "Mechanics and engineering graphics". At the moment he is working on his dissertation "Development of the system of thermal preparation of hydraulic units of mobile agricultural machinery".

Ramzid Akhmarov has PhD degree in Technical Sciences. Now he is working as assistant professor at department "Mechanics and engineering graphics". He has published 32 scientific works in central journals and inter-university collections. He's working on his doctoral dissertation. Author of many educational and methodical developments. He takes part in public events of the department, faculty, university. Constantly working on improving his pedagogical skills. Under his leadership, the students of the Mechanical Department became winners of the AllRussian Olympiad in resistance of materials and machine parts.

Article submitted 2020-03-18. Resubmitted 2020-04-27. Final acceptance 2020-04-29. Final version published as submitted by the authors. 